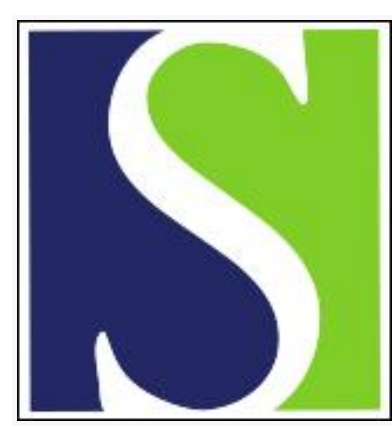

Scand J Work Environ Health 1997;23(3):227-231

https://doi.org/10.5271/sjweh.203

Issue date: Jun 1997

Airway isocyanate-adducts in asthma induced by exposure to hexamethylene diisocyanate

by Redlich CA, Karol MH, Graham C, Homer RJ, Holm CT, Wirth JA, Cullen MR

Key terms: isocyanate adducts; occupational asthma

This article in PubMed: www.ncbi.nlm.nih.gov/pubmed/9243734

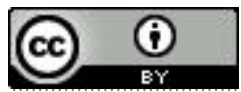




\title{
Airway isocyanate-adducts in asthma induced by exposure to hexamethylene diisocyanate
}

\author{
by Carrie A Redlich, MD, ${ }^{1}$ Meryl H Karol, PhD, ${ }^{2}$ Cynthia Graham, ${ }^{2}$ Robert J Homer, MD, ${ }^{3,4}$ \\ Carole T Holm, ${ }^{5}$ Joel A Wirth, MD, Mark R Cullen, MD ${ }^{1}$
}

Redlich CA, Karol MH, Graham C, Homer RJ, Holm CT, Wirth JA, Cullen MR. Airway isocyanate-adducts in asthma induced by exposure to hexamethylene diisocyanate. Scand J Work Environ Health 1997;23(3):227-31.

\begin{abstract}
Objectives The clinical features, airway histology, and detection of hexamethylene diisocyanate (HDI) protein adducts in endobronchial biopsies from a patient with HDI asthma are described.

Methods Isocyanate asthma was diagnosed by history, methacholine challenge, and workplace HDI challenge. Bronchoscopy was performed $24 \mathrm{~h}$ after challenge and immunohistochemical staining was performed.

Results Airway biopsies obtained at bronchoscopy demonstrated inflammatory changes typical for asthma, including increased airway eosinophils and T cells. Immunohistochemical staining with specific anti-HDI antibodies demonstrated the presence and localization of HDI adducts in human bronchial biopsies.

Conclusions These studies confirm epithelial exposure to HDI following workplace challenge and demonstrate the feasibility of detecting and localizing isocyanate adducts in human lung tissue. Identifying and characterizing the airway macromolecules to which isocyanates bind in vivo are probably crucial to the understanding of how isocyanates cause sensitization and asthma. The ability to detect isocyanate adducts may also help characterize isocyanate exposure patterns and exposure-disease relationships.
\end{abstract}

Key terms isocyanate adducts, occupational asthma.

Diisocyanates are a group of highly reactive, widely used low-molecular weight chemicals that can cause asthma after exposure to vapors or aerosols (1). Isocyanate asthma has been difficult to diagnose and control, in part because the mechanisms by which isocyanates cause asthma and the determinants of exposure have not been well defined (2-4). Most of the prior clinical and animal investigations have involved methylene diphenyl diisocyanate (MDI) and toluene diisocyanate (TDI), rather than hexamethylene diisocyanate (HDI), which is increasingly being used in place of TDI (4-10). To our knowledge, none of the diisocyanates have previously been identified or localized in the human respiratory tract. Karol et al $(11,12)$ have measured TDI-protein conjugates using a guinea pig model of TDI sensitivity.
TDI-adducted proteins were observed in the airways and bronchoalveolar lavage (BAL) fluid after exposure to TDI vapor $(11,12)$. TDI-adducted hemoglobin has also been detected in erythrocytes of sensitized guinea pigs (13).

In this report we describe the detection of HDI protein adducts in an airway biopsy from an autobody shop worker with HDI asthma following workplace challenge with HDI. This is the first time isocyanate adducts have been identified in human airway biopsies that we are aware of. Airway histology and immunohistochemistry revealed an increased number of total inflammatory cells, basement membrane thickening, and increased numbers of T cells, consistent with findings in cases of MDI- and TDI-induced asthma.

Occupational and Environmental Medicine Program, Department of Internal Medicine, Yale University School of Medicine, New Haven, Connecticut, United States.

2 Department of Environmental and Occupational Health, Center for Environmental and Occupational Health and Toxicology, University of Pittsburgh, Pittsburgh, United States.

3 VA Connecticut Healthcare System, Pathology and Laboratory Medicine Service, West Haven, Connecticut, United States.

4 Department of Pathology, Yale University School of Medicine, New Haven, Connecticut, United States.

5 Pulmonary and Critical Care Section, Department of Internal Medicine, Yale University School of Medicine, New Haven, Connecticut, United States.

Reprint requests to: Dr Carrie A Redlich, Yale Occupational and Environmental Medicine Program, 135 College St, 3rd Floor, New Haven, CT 06510, USA. 


\section{Case report}

The patient was a 25 -year-old man with no history of childhood asthma, allergies, or atopy. At 16 years of age he started to work in an autobody shop and at 20 years of age he started his own autobody shop business. Since 19 years of age he had noted the gradual onset of evening cough and wheeze after working in the autobody shop. These symptoms progressed, and several years before admission he was diagnosed with asthma and started on inhaled bronchodilators. His work entailed repairing damaged cars, including spray painting with materials containing HDI monomer and several HDI oligomers (prepolymers). He used a respirator and spray booth for major jobs. He was a life-time nonsmoker.

In 1995 he was seen at the Yale Occupational and Environmental Medicine Clinic for the evaluation of possible isocyanate asthma. Full pulmonary function tests showed normal forced expiratory volume in $1 \mathrm{~s}\left(\mathrm{FEV}_{1.0}\right)$,

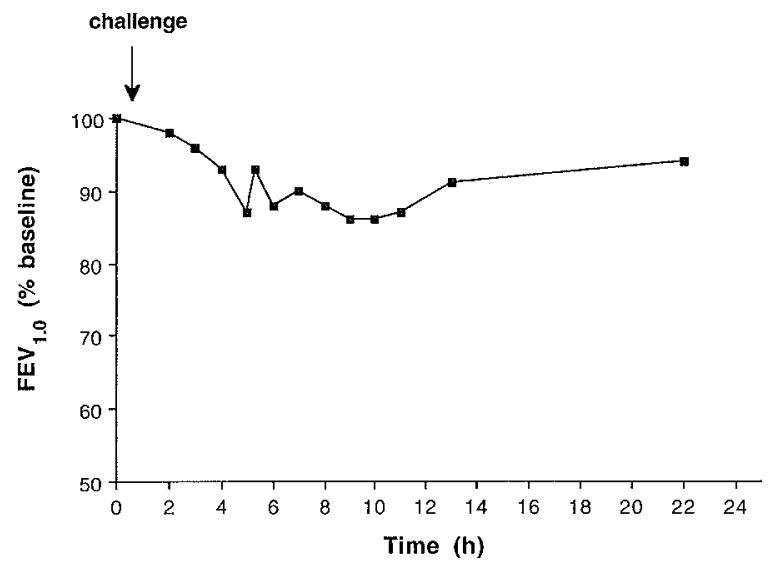

Figure 1. Workplace challenge to hexamethylene diisocyanate (HDI) of forced expiratory volume in $1 \mathrm{~s}\left(\mathrm{FEV}_{10}\right)$. Masurements were obtained at base line and hourly following the inhalation challenge until bed time and before bronchoscopy (at $24 \mathrm{~h}$ after challenge)

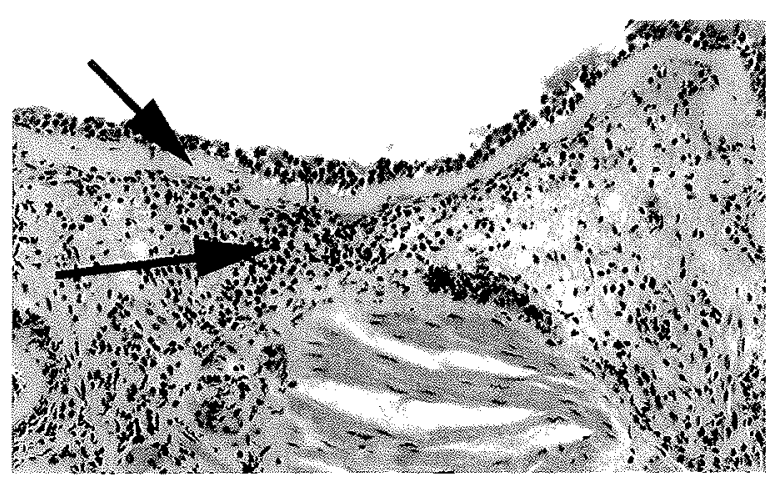

Figure 2. Histologic changes in the airway by endobronchial biopsy obtained from the patient after exposure to hexamethylene diisocyanate (HDI). Note the epithelial desquamation, subepithelial fibrosis (short arrow) and submucosal inflammatory infiltrate (long arrow). The infiltrate is rich in eosinophils and lymphocytes. (Hematoxylin and eosin, original magnification $200 \mathrm{X}$ ) forced vital capacity $(\mathrm{FVC})$, the $\mathrm{FEV} \%\left[\left(100 \times \mathrm{FEV}_{1.0}\right)\right.$ FVC], lung volumes, and diffusing capacity. Methacholine challenge testing showed significant airway hyperresponsiveness with a $50 \%$ drop in $\mathrm{FEV}_{1.0}$ after an inhaled methacholine dose of $5 \mathrm{mg} / \mathrm{ml}$. Peak expiratory flow recording was attempted, but the patient had difficulty with compliance. An examination of material safety data sheets confirmed the presence of HDI monomer and oligomers during the use of the paints in the body shop.

\section{Methods and results}

A workplace exposure to the patient's own work materials was conducted, during which the patient spray painted a car without respiratory protection for $40 \mathrm{~min}$. Industrial hygiene air sampling documented average HDI levels of $13 \mathrm{ppb}$ isocyanate prepolymer for $40 \mathrm{~min}$. The handheld real-time instrument could not distinguish between HDI monomer (vapor phase) and oligomers (aerosol phase). The exposure was followed by hourly spirometry and observation. The patient reacted to the HDI challenge with symptomatic changes consistent with a late asthmatic response. As shown in figure 1, the patient had a delayed spirometric response with a maximal drop in $\mathrm{FEV}_{1.0}$ of $14 \%$, occurring 9-10 $\mathrm{h}$ after the exposure, which was temporarily associated with symptoms of cough and shortness of breath.

Twenty-four hours after the HDI challenge, the patient underwent bronchoscopy (Pentax fiberoptic bronchoscope), including BAL and multiple endobronchial airway biopsies taken from the primary, secondary, and tertiary carinas. BAL of the left lingula with $250 \mathrm{~cm}^{3}$ saline $\left(50 \mathrm{~cm}^{3}\right.$ times 5) yielded $24.6 \times 10^{6}$ cells with $87 \%$ macrophages, $9 \%$ lymphocytes, $1 \%$ eosinophils, and $3 \%$ polymorphonuclear cells. Light microscopy of the airway biopsies showed increased numbers of total inflammatory cells and eosinophils in the epithelium and submucosa and increased basement membrane thickness in a comparison with biopsies obtained from nonasthmatic nonsmoking referents (figure 2, table 1). Immunohistochemistry for CD45 (total lymphocytes) and CD3 (T cells) showed increased numbers of these cells when compared with the results of nonasthmatic referents (table 1, figure $3 \mathrm{~A}$ ). CD25 staining (interleukin-2 receptor) showed that these cells are activated, a key feature that distinguishes lymphoid infiltrates of nonasthmatic airways from asthmatic airways (figure 3B) (14).

Radioallergosorbent (RAST) assays were performed for immunoglobulin (Ig)E specific to TDI, MDI and HDI, as well as enzyme-linked immunosorbent assays (ELISA) for IgG specific to TDI, HDI, and MDI. No HDI-specific antibodies of either the IgE or IgG class were detected. However, the patient had a markedly elevated total $\mathrm{IgE}$ of $1430 \mathrm{IU} / \mathrm{ml}$. 
Table 1. Airway histology and immunohistochemistry.

\begin{tabular}{|c|c|c|c|c|c|c|c|c|}
\hline \multirow[t]{3}{*}{ Parameter } & \multirow{2}{*}{\multicolumn{2}{|c|}{$\begin{array}{l}\text { Basement membrane } \\
\text { thickness }(\mu)^{\mathrm{a}}\end{array}$}} & \multicolumn{6}{|c|}{ Inflammatory cells ${ }^{b}$} \\
\hline & & & \multicolumn{2}{|c|}{ Eosinophils } & \multicolumn{2}{|c|}{ Total lymphocytes } & \multicolumn{2}{|c|}{ T-cells } \\
\hline & Mean & Range & Mean & Range & Mean & Range & Mean & Range \\
\hline $\begin{array}{l}\text { Patient } \\
\text { Referents }(N=5)\end{array}$ & $\begin{array}{r}13.14 \\
3.44\end{array}$ & $2.41-4.86$ & $\begin{array}{r}85 \\
5\end{array}$ & $0-13$ & $\begin{array}{l}635 \\
307\end{array}$ & $182-437$ & $\begin{array}{l}577 \\
169\end{array}$ & $18-390$ \\
\hline
\end{tabular}

a Five to 8 biopsies per subject were analyzed using hematoxylin and eosin staining. The total area of a section of basement membrane was measured and divided by its length. The results are expressed as average in microns.

${ }^{b}$ Cells within $125 \mu$ of the surface epithellum were counted. Two biopsies were stained for total lymphocytes (CD45) and total T cells (CD3). Results are expressed as the average number of cells per square millimeter.

Figure 3. Immunohistochemical findings in the airway biopsy. Figure $3 A$ shows staining for $\mathrm{CD} 3$, a marker for T cells. Note intraepithelial T cells (short arrow) and submucosal Tcells (long arrow). Subepithelial fibrosis is seen as the area devoid of $\mathrm{T}$ cells (medium arrow). Figure $3 \mathrm{~B}$ shows staining for $\mathrm{CD} 25$ (the $1 \mathrm{~L} 2$ receptor), a marker of recent $\mathrm{T}$ cell activation. Positive staining cells can be seen in the submucosa (arrows). (Diaminobenzidene developed immunostain, counterstained with hematoxylin, original magnification 200X)

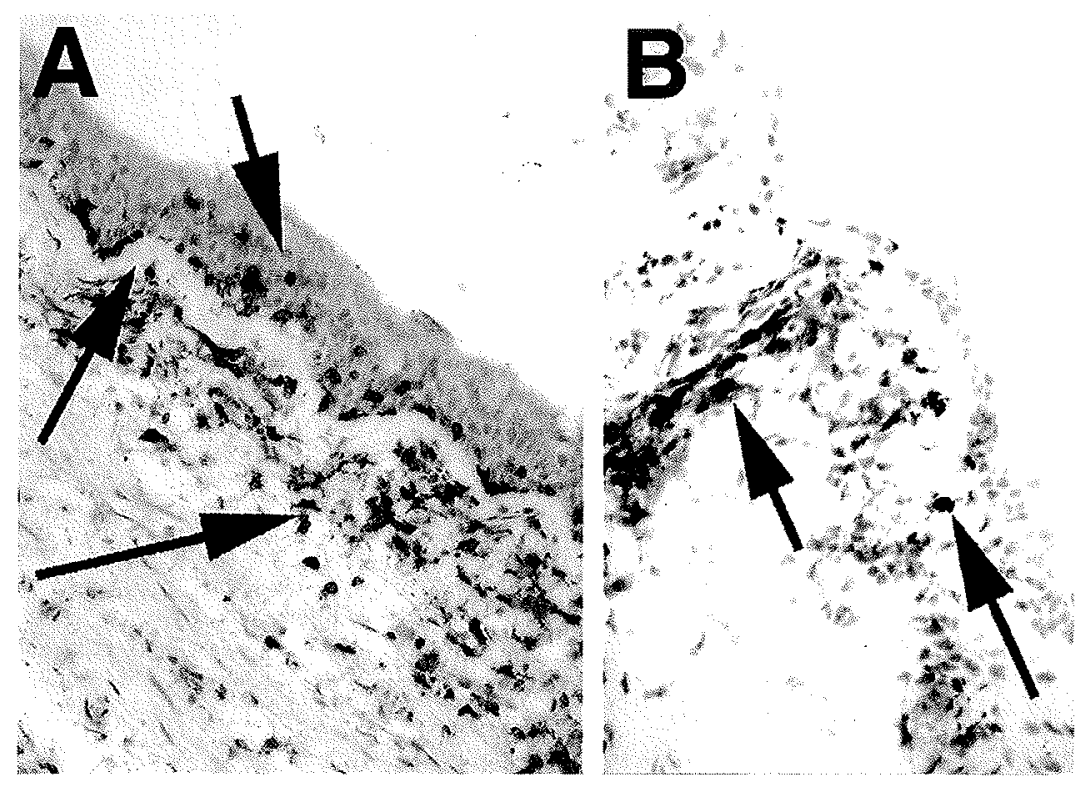

HDI adducts (HDI-bound proteins) were readily detected in the airway biopsies employing staining with rabbit anti-HDI ovalbumin (OA) antiserum (1:200 dilution), followed by biotinylated goat antirabbit $\mathrm{IgG}$ (1:300), avidin-biotin-horse radish complex, and then 3,3'-diaminobenzidine (figure 4A). The antiserum was obtained from rabbits which had been repeatedly injected intradermally with a total of $2 \mathrm{mg}$ of HDI-ovalbumin (HDI-OA) distributed among multiple sites along the shaved back. The animals were boosted with an equal quantity of antigen 3 weeks later, and sera were drawn after another week. The specificity of the antiserum was demonstrated by dot-blot assays, in which it was found to react with HDI-adducted proteins (HDI-OA, HDIhuman serum albumin, and HDI-guinea pig serum albu$\mathrm{min}$ ), but not with the unadducted serum albumins, and by inhibition studies. In the latter, complete inhibition of reaction was obtained with HDI-OA, but not with OA. The adducts were primarily localized to the apical surface of the airway epithelium (figure 4B). No staining was observed with biopsies from normal age-matched human lung from a nonsmoker. The specificity of the staining reaction for HDI was verified by inhibition studies. Staining was prevented by the addition of HDI-OA, but not $\mathrm{OA}$, to the primary staining solution (figure $4 \mathrm{C}$ ). These results clearly confirmed epithelial exposures to HDI following workplace challenge and demonstrate the feasibility of detecting isocyanate adducts in human lung tissues. Further studies are in progress to confirm and identify the protein adduct. No HDI adducts were detectable in serum.

\section{Discussion}

Isocyanates account for about $25 \%$ of all reported cases of occupational asthma in developed countries. How exposure to isocyanates leads to isocyanate sensitization and asthma has been poorly defined. Studies to date, largely on TDI- and MDI-exposed patients, have found airway inflammation and suggest that isocyanate asthma is immunologically mediated predominantly through non-IgE mechanisms $(1,2,7,15)$.

Our case is noteworthy in several respects. This is the first report demonstrating the presence and localization 

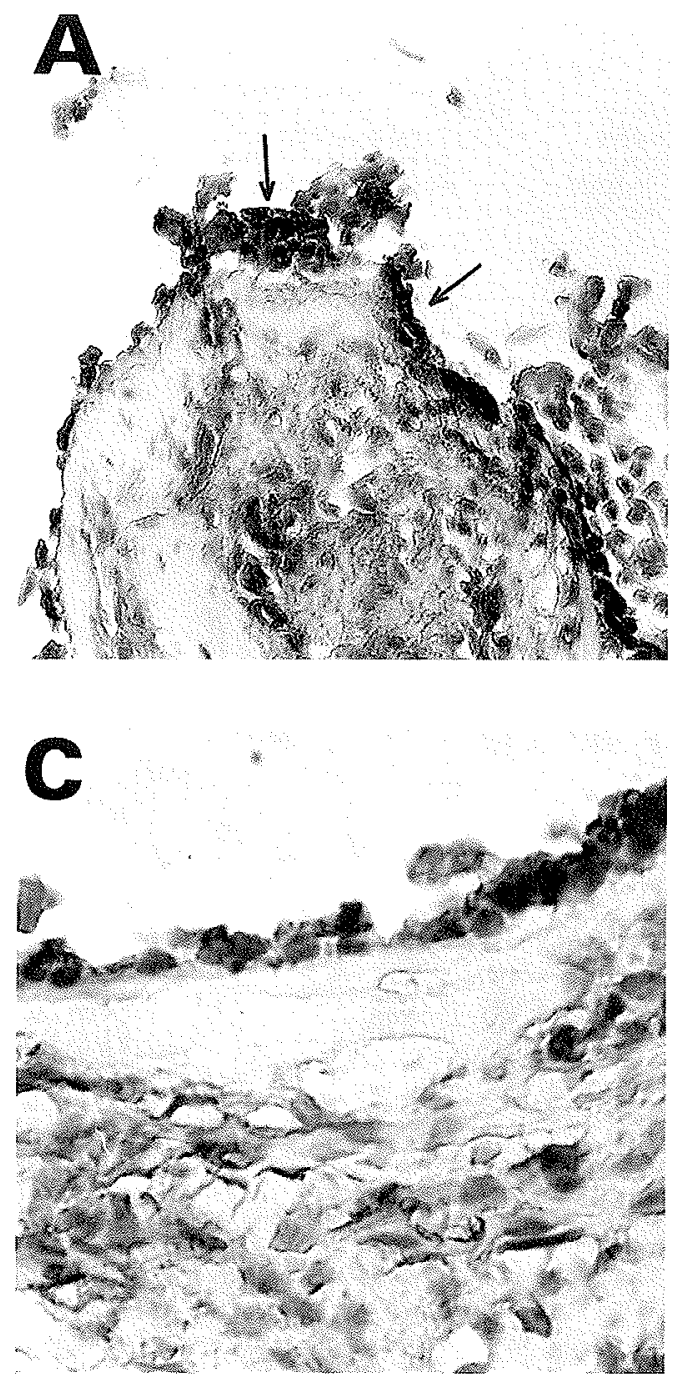

of isocyanate adducts in human airways. Binding of the specific HDI antigen to the airways is probably involved in initiating the immunologic responses to isocyanates. Identifying and localizing HDI protein adducts formed in vivo may help elucidate the sequence of events in the sensitization and development of asthma. These studies clearly confirm airway epithelial exposure to HDI after workplace challenge and demonstrate the feasibility of detecting and localizing isocyanate adducts in human lung tissues.

As HDI exposure may occur as an aerosol, it is not surprising to find HDI adducts on the proximal airway epithelium. The lack of serum albumin HDI adducts is not unexpected given the inhalational route of exposure and the high reactivity of the isocyanate. TDI adducts have been detected in the airways, BAL fluid, and erythrocytes of guinea pigs exposed to 1 to $2 \mathrm{ppm}$ of TDI vapor $(11,12,13)$. Our findings from a human after HDI exposure (13 ppb) are similar to those in TDI sensitized guinea pigs in that adducts were localized primarily

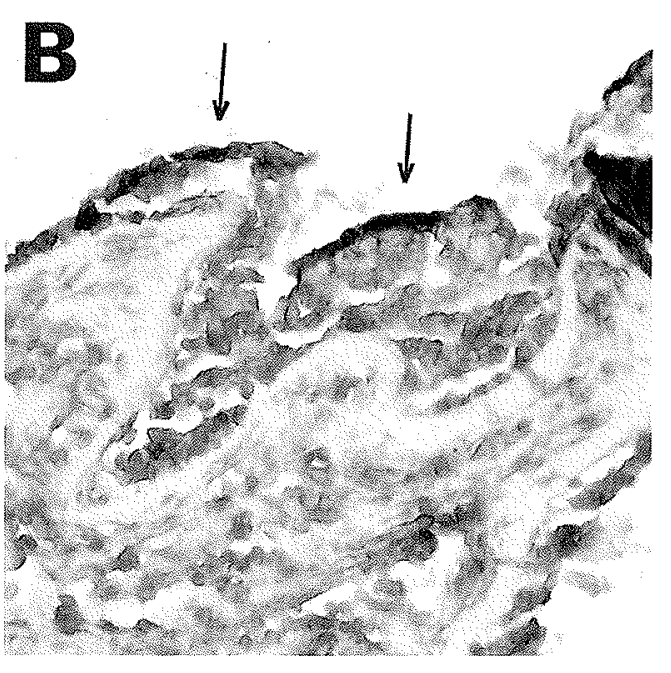

Figure 4. Immunohistochemical demonstration of adducts to hexamethylene diisocyanate (HDI) in the airway biopsy. Figure $4 \mathrm{~A}$ shows immunohistochemical staining for the $\mathrm{HD}$ adducts on the bronchial epithelium [rabbit anti-HDI ovalbumin antiserum (arrow) used]. Diaminobenzidene developed immunostain, original magnification 400X. Figure 4B shows the immunohistochemical staining for $\mathrm{HDI}$ adducts at a higher magnification (original magnification 1000X), largely localized to the apical surface of the airway epithelium (arrow). Figure $4 \mathrm{C}$ demonstrates the lack of immunohistochemical staining with the addition of HDI-OA in the same patient, original magnification 1000X.

to the airway epithelium. It is possible that the detection of serum HDI adducts may require higher levels of exposure.

This report adds to the emerging knowledge regarding the histology and inflammatory response in HDIinduced asthma. Malo (16) has previously reported inflammatory changes including increased numbers of neutrophils, lymphocytes, and eosinophils in the bronchial biopsies of subjects with HDI asthma 3 to 24 weeks after removal from exposure. We have shown impressive airway inflammation with marked basement membrane thickening and increased eosinophils and total and activated (CD25+) T lymphocytes in airway biopsies taken after workplace challenge. Most clinical and animal studies on isocyanates have involved subjects exposed to TDI vapor, the first agent in wide use (4). Much less is known about HDI, now more widely used than TDI in many settings (17). Since diisocyanates differ in their physical properties (eg, vapor pressure) chemical reactivity, and biological properties (4), it is unclear whether 
HDI, which, when used, may result in aerosol or vapor phase exposures or both, behaves similarly to the TDI vapors, or to the largely aerosol phase of MDI.

This is the first demonstration of the detection and localization of isocyanate adducts in human lung tissues. Together with further characterization of the inflammatory response, such information should provide important insights into macromolecules that are adducted and into their role in the sensitization and pathogenesis of HDI asthma. Isocyanate adducts are also potentially important biomarkers for the documentation of exposure and may help characterize exposure patterns and exposure-disease relationships. As such, they may prove to be important tools in the future for the diagnosis and prevention of this prevalent disorder.

\section{Acknowledgments}

This work was supported by grant NIH KO8 HL03129 and the Yale Adult General Clinical Research Center.

\section{References}

1. Chan-Yeung M, Malo J-L. Occupational asthma, N Engl J Med 1995;333:107-11.

2. Fabbri LM. Airway inflammation in occupational asthma. Am J Respir Crit Care Med 1994;150:S80 - 2.

3. Malo JL, Ghezzo H, L'Archeveque J, Lagier F, Perrin B, Cartier $\mathrm{A}$. Is the clinical history a satisfactory means of diagnosing occupational asthma? Am Rev Respir Dis 1991;143: $528-32$.

4. Vandenplas O, Malo JL, Saetta M, Mapp CE, Fabbri LM. Occupational asthma and extrinsic alveolitis due to isocyanates: current status and perspectives. Br J Ind Med 1993;50: 213-28.

5. Fabbri LM, Saetta M, Picotti G, Mapp CE. Late asthmatic reactions, airway inflammation and chronic asthma in toluene-diisocyanate-sensitized subjects. Respiration 1991;1:1821.

6. Paggiaro P, Bacci E, Paoletti P, Dente FL, Marchetti G, Talini $\mathrm{D}$, et al. Bronchoalveolar lavage and morphology of the airways after cessation of exposure in asthmatic subjects sensi- tized to toluene diisocyanate. Chest $1990 ; 98: 536-42$.

7. Bentley AM, Maestrelli P, Saetta M, Fabbri LM, Robinson DS, Bradley BL, et al. Activated T-lymphocytes and eosinophils in the bronchial mucosa in isocyanate-induced asthma. J Allergy Clin Immunol 1992;89:821-9.

8. Saetta M, Maestrelli P, Turato G, Milani G, Pivirotto F, Fabbri LM, et al. Airway wall remodeling after cessation of exposure to isocyanates in sensitized asthmatic subjects. Am J Respir Crit Care Med 1995;151:489-94.

9. Saetta M, Di Stefano A, Maestrelli P, De Marzo N, Milani GF, Pivirotto F, et al. Airway mucosal inflammation in occupational asthma induced by toluene diisocyanate. Am Rev Respir Dis 1992;145:160 - 8 .

10. Karol MH. Animal models of occupational asthma. Eur Respir J 1994;7:555-68.

11. Jin R, Day BW, Karol MH. Toluene diisocyanate protein adducts in the bronchoalveolar lavage of guinea pigs exposed to vapors of the chemical. Chem Res Toxicol 1993;6:90612.

12. Jin R, Karol MH. Identification of toluene diisocyanate-adducts in tissues of sensitized guinea pigs. Am J Respir Crit Care Med 1994;149:A850.

13. Day BW, Jin R, Karol MH. In Vivo and in Vitro reactions of toluene diisocyanate isomers with guinea pig hemoglobin. Chem Res Toxicol 1996;9:568-73.

14. Bradley BL, Azzawi M, Jacobson M, Assoufi B, Collins JV, Irani AMA, et al. Eosinophils, T lymphocytes, mast cells, neutrophils, and macrophages in bronchial biopsy specimens from atopic subjects with asthma: comparison with atopic subjects without asthma and normal control subjects. J Allergy Clin Immunol 1991; 88:661-74.

15. Mapp CE, Saetta M, Maestrelli P, Di Stefano A, Chitano P, Boschetto $P$, et al. Mechanisms and pathology of occupational asthma. Eur Respir J 1994;7:544-54.

16. Boulet LP, Boulet M, Laviolette M, Dugas M, Milot J, Leblanc $\mathrm{C}$, et al. Airway inflammation after removal from the causal agent in occupational asthma due to high and low molecular weight agents. Eur Respir J 1994;7:1567-75.

17. Myer HE, O'Block ST, Dharmarajan V. A survey of airborne HDI, HDI-based polyisocyanate and solvent concentrations in the manufacture and application of polyurethane coatings. Am Ind Hyg Assoc J 1993;54:663—670.

Received for publication: 2 July 1996 